Int. J. Electrochem. Sci., 12 (2017) $6068-6080$

\title{
Improved Cycling Stability of Three-state Electrochromic Devices with Uniformly Dip-coated Electrode Surface
}

\author{
L. Wu, D.J. Yang, C.J. Hu, S. Liu, Q.G. Chen, J.Y. Shi, F. Wu, Y. Xiang* \\ School of Energy Science and Engineering, University of Electronic Science and Technology of \\ China, 2006 Xiyuan Ave, West High-Tech Zone, Chengdu, Sichuan 611731, China. \\ *E-mail: xyg@uestc.edu.cn
}

doi: $10.20964 / 2017.07 .14$

Received: 20 February 2017 / Accepted: 16 April 2017 / Published: 12 June 2017

\begin{abstract}
The electrodeposition-based three-state electrochromic device with its electrode surface modified by dip-coated titanium dioxide $\left(\mathrm{TiO}_{2}\right)$ thin films shows significantly improved cycling stability compared to the device modified with spin-coated ones. The decrement rate of optical transmittance contrast for spin-coated device after 1500 cycles is reduced significantly from $66 \%$ to $28 \%$ for dip-coated device, indicating $~ 60 \%$ improvement. A comparative study of the structural and morphological features of dip- and spin-coated $\mathrm{TiO}_{2}$ thin films reveals that the surface uniformity of dip-coated device is much better than that of spin-coated one, leading to an improved overall surface roughness, which is a primary factor of the cycling stability. Although the difference in the surface roughness is marginal for the smooth parts of both the dip- and spin-coated $\mathrm{TiO}_{2}$ thin films, the improved uniformity of the dipcoated $\mathrm{TiO}_{2}$ thin film surface is conducive to the quick dissolution of $\mathrm{Ag}$ back into electrolyte during the switching between the coloration and bleaching states thanks to the reduced locally residual Ag around or into the rough regions caused by $\mathrm{TiO}_{2}$ nanoparticles agglomeration.
\end{abstract}

Keywords: Electrodeposition; Electrochromic; Dip-coating; Uniformity; Cycling stability

\section{$\underline{\text { FULL TEXT }}$}

(C) 2017 The Authors. Published by ESG (www.electrochemsci.org). This article is an open access article distributed under the terms and conditions of the Creative Commons Attribution license (http://creativecommons.org/licenses/by/4.0/). 